\title{
The 4th World Landslide Forum: Landslide Research and Risk Reduction for Advancing the Culture of Living with Natural Hazards
}

\author{
Irasema Alcántara-Ayala ${ }^{1}$ Kyoji Sassa ${ }^{2}$ Matjaž Mikoš $^{3}$ Quinli Han ${ }^{4,5}$. \\ Jakob Rhyner ${ }^{6,7}$ - Kaoru Takara ${ }^{8}$ Satoru Nishikawa' Badaoui Rouhban $^{10}$. \\ Sálvano Briceño ${ }^{11}$
}

Published online: 18 September 2017

(C) The Author(s) 2017. This article is an open access publication

\begin{abstract}
The World Landslide Forum is a triennial mainstream conference that gathers together the scientific and technological community, policymakers, industry actors, public officials, and other stakeholders, who deal with the understanding and management of landslide disaster risk. The establishment of the ISDR-ICL Sendai Partnerships 2015-2025 for Global Promotion of Understanding and Reducing Landslide Disaster Risk in Sendai during the 2015 World Conference on Disaster Risk
\end{abstract}

Irasema Alcántara-Ayala

irasema@igg.unam.mx

1 Institute of Geography, National Autonomous University of Mexico (UNAM), 04510 Mexico City, Mexico

2 International Consortium on Landslides, Kyoto University, Kyoto 611-0011, Japan

3 Faculty of Civil and Geodetic Engineering, University of Ljubljana, 1000 Ljubljana, Slovenia

4 International Consortium on Landslides, IPL Global Promotion Committee, Kyoto 611-0011, Japan

5 Division of Ecological and Earth Sciences, The United Nations Educational, Scientific and Cultural Organization (UNESCO), 75352 Paris, France

6 United Nations University, 53113 Bonn, Germany

7 Institute for Environment and Human Security (UNU-EHS), United Nations University, 53113 Bonn, Germany

8 Disaster Prevention Research Institute (DPRI), Kyoto University, Kyoto 611-0011, Japan

9 Japan Center for Area Development Research, Tokyo 105-0001, Japan

10 International Programme on Landslides, Kyoto 611-0011, Japan

11 Science Committee, Integrated Research on Disaster Risk (IRDR), 01220 Divonne-les-Bains, France
Reduction (WCDRR) enabled the landslide science and technology community support the implementation of the Sendai Framework for Disaster Risk Reduction 2015-2030 in order to prevent new and reduce existing disaster risk. The 4th World Landslide Forum (WLF4) was held in Ljubljana, Slovenia, from 29 May to 2 June 2017 and discussed the progress of landslide research and risk reduction for advancing the culture of living with natural hazards. A high-level panel composed of United Nations officials, international stakeholders, and national organizations sought to identify the best mechanisms to be developed by the community of the International Consortium on Landslides (ICL). The objective was to advance the implementation of the ISDR-ICL Sendai Partnerships, to achieve a better commitment among partners, and to provide substantive services to developing countries. During the WLF4, the 2017 Ljubljana Declaration on Landslide Risk Reduction was adopted and the concept framework of the Kyoto 2020 Commitment was endorsed.

Keywords Disaster risk reduction - Kyoto

Commitment · Landslide risk assessment · Ljubljana

Declaration $\cdot$ Sendai Partnerships

\section{Antecedents of the International Consortium on Landslides}

The International Consortium on Landslides (ICL) is an international, nongovernmental, and nonprofit scientific organization composed of landslide experts and representatives from international parties associated with disaster risk reduction (DRR). Established during a symposium in Kyoto, 21-25 January 2002, the ICL has been supported by the United Nations Educational, Scientific and Cultural 
Organization (UNESCO), the World Meteorological Organization (WMO), the Food and Agriculture Organization of the United Nations (FAO), the United Nations Office for Disaster Risk Reduction (UNISDR), the International Union of Geological Sciences (IUGS), and the Ministry of Education, Culture, Sports, Science and Technology and the Ministry of Foreign Affairs of Japan (Sassa 2004a). Support is also currently provided by the United Nations University (UNU), the International Council for Science (ICSU), the World Federation of Engineering Organizations (WFEO), and the International Union of Geological Sciences (IUGS).

The objectives of the Consortium are to:

1. promote landslide research for the benefit of society and the environment, and capacity building, including education, notably in developing countries;

2. integrate the geosciences and technology within the appropriate national cultural and social contexts in order to evaluate landslide risk in urban, rural, and developing areas including cultural and natural heritage sites, as well as to contribute to the protection of the natural environment and sites of high societal value;

3. combine and coordinate international expertise in landslide risk assessment and mitigation studies, thereby resulting in an effective international organization, which will act as a partner in various international and national projects; and

4. promote a global, multidisciplinary program on landslides.

Several activities are carried out on a regular basis under the umbrella of ICL. These include the University Twinning and Networking (UNITWIN) Cooperation Programme on landslide risk mitigation for society and the environment with UNESCO and Kyoto University, the publication of the journal Landslides, the International Programme on Landslides (IPL) (Sassa 2004b), the World Landslide Forum (WLF) held every 3 years (Table 1) (Sassa 2009, 2017a; Sassa et al. 2012, 2015), the identification of World Centers of Excellence on Landslide Risk Reduction (WCoEs) at each WLF, and the support of the IPL Global Promotion Committee (IPL-GPC) to manage the IPL, WLF, and WCoEs. The IPL is the central activity of ICL and it aims to conduct international cooperative research and capacity building on landslide risk mitigation, notably in developing countries, particularly by contributing to the International Strategy for Disaster Reduction (ISDR). ${ }^{1}$

\footnotetext{
${ }^{1}$ Further details on ICL can be found in Sassa (2006, 2012, 2016) and http://icl.iplhq.org/category/home-icl/.
}

\section{The 4th World Landslide Forum, Ljubljana, Slovenia}

Looking towards the progress of landslide research and risk reduction for advancing the culture of living with natural hazards, 610 participants from 51 countries attended the 4th World Landslide Forum (WLF4) in Ljubljana, 29 May2 June 2017. The WLF4 involved experts on disaster risk reduction from different backgrounds and disciplines. Members from universities and academic research institutions, government scientific research institutes and centers, geological surveys, civil protection agencies, international organizations, civil society, private sector, and students discussed the five themes of the Forum: (1) Sendai Partnerships 2015-2025; (2) Advances in Landslide Science; (3) Advances in Landslide Technology; (4) Diversity of Landslide Forms; and (5) Landslides in Different Environments.

Understanding and reducing landslide disaster risk was addressed by four Forum Lectures on: (1) Rupestrian ${ }^{2}$ world heritage sites: instability investigation and sustainable mitigation; (2) Rock fall occurrence and fragmentation; (3) Glacial lake outburst floods; and (4) Landslides and society. An additional special session was devoted to the International Programme on Landslides in which activities and progress of the WCoEs and IPL projects were presented by the corresponding leaders. The objective of the session was to analyze the strengths and weaknesses of current contributions to landslide disaster research and landslide disaster risk reduction.

A high-level panel discussion was organized to discuss strengthening research and government networking in nations susceptible to landslides, particularly developing countries, in order to support landslide disaster risk reduction endeavors. This cooperative program requires joint efforts on the part of governments, United Nations organizations, international nongovernment organizations (NGOs), and the world scientific and technical community. Thus, these entities were called upon to discuss the necessary and immediate steps needed to move towards an effective implementation of the ISDR-ICL Sendai Partnerships 2015-2025 and to support the IPL as its infrastructure (Sassa 2017a). Participants in the high-level panel sought to identify the best mechanisms to be developed by the ICL community in order to advance the implementation of the ISDR-ICL Sendai Partnerships, to achieve a better commitment among partners, and to provide substantive services to developing countries.

Reference was made to several actions and targets (Sassa 2017a), which offered several viable strategic lines of engagement. These initiatives included the identification

\footnotetext{
$\overline{{ }^{2} \text { Composed }}$ of rock: inscribed on rocks.
} 
Table 1 Summary of the World Landslide Fora organized by ICL

\begin{tabular}{|c|c|c|c|}
\hline World Landslide Fora & Goals & Main Outcome & $\begin{array}{l}\text { Linkages to the International Agenda on } \\
\text { DRR }\end{array}$ \\
\hline $\begin{array}{l}\text { WLF1, Tokyo, Japan, } \\
2008\end{array}$ & $\begin{array}{l}\text { Promotion of research and exchange of } \\
\text { experience through open forums, } \\
\text { symposia, and workshops } \\
\text { Advances and achievements of IPL in } \\
\text { terms of technology development, } \\
\text { targeted landslides: mechanisms and } \\
\text { impacts, capacity building, and } \\
\text { mitigation, preparedness, and } \\
\text { recovery }\end{array}$ & $\begin{array}{l}\text { The } 2008 \text { Tokyo Declaration, } \\
\text { Strengthening the } \\
\text { International Program on } \\
\text { Landslides (IPL) with } \\
\text { UNISDR }\end{array}$ & $\begin{array}{l}\text { Hyogo Framework for Action 2005- } \\
\text { 2015: Building the Resilience of } \\
\text { Nations and Communities to } \\
\text { Disasters }\end{array}$ \\
\hline $\begin{array}{l}\text { WLF2, Rome, Italy, } 2011 \\
\text { Putting science into } \\
\text { practice }\end{array}$ & $\begin{array}{l}\text { Providing a global cross-cutting } \\
\text { information and cooperation platform } \\
\text { with which all diverse stakeholders } \\
\text { can contribute to landslide research, } \\
\text { practice, education, and decision } \\
\text { making, to strengthen landslide and } \\
\text { other related Earth system risk } \\
\text { reduction strategies } \\
\text { The actual implementation of } \\
\text { technology and research in everyday } \\
\text { applications and procedures with the } \\
\text { direct involvement of researchers, } \\
\text { engineers, private enterprises, } \\
\text { stakeholders, as well as policy and } \\
\text { decision makers as a major endeavor }\end{array}$ & & $\begin{array}{l}\text { Hyogo Framework for Action 2005- } \\
\text { 2015: Building the Resilience of } \\
\text { Nations and Communities to } \\
\text { Disasters }\end{array}$ \\
\hline $\begin{array}{l}\text { WLF3, Beijing, China, } \\
2014 \\
\text { Towards a safer geo- } \\
\text { environment }\end{array}$ & $\begin{array}{l}\text { Providing an information and academic } \\
\text { exchange platform for landslide } \\
\text { researchers and practitioners by } \\
\text { creating an opportunity to promote } \\
\text { worldwide cooperation and to share } \\
\text { new theories, technologies, and } \\
\text { methods in the fields of landslide } \\
\text { survey/investigation, monitoring, } \\
\text { early warning, prevention, and } \\
\text { emergency management }\end{array}$ & $\begin{array}{l}\text { The } 2014 \text { Beijing Declaration } \\
\text { (BD), Landslide Risk } \\
\text { Mitigation: Toward a Safer } \\
\text { Geoenvironment }\end{array}$ & $\begin{array}{l}\text { The BD aiming at establishing the ICL- } \\
\text { IPL Sendai Partnerships at the 2015 } \\
\text { World Conference on Disaster Risk } \\
\text { Reduction (WCDRR), Sendai, Japan, } \\
\text { March } 2015\end{array}$ \\
\hline $\begin{array}{l}\text { WLF4, Ljubljana, } \\
\text { Slovenia, } 2017 \\
\text { Landslide research and } \\
\text { risk reduction for } \\
\text { advancing the culture of } \\
\text { living with natural } \\
\text { hazards }\end{array}$ & $\begin{array}{l}\text { Contributing to the ISDR-ICL Sendai } \\
\text { Partnerships } 2015-2025 \text { for disaster } \\
\text { risk reduction, and stressing society's } \\
\text { attitude to landslides } \\
\text { Strengthening advances in landslide } \\
\text { science and technology, diversity of } \\
\text { landslide forms, and landslides in } \\
\text { different environments }\end{array}$ & $\begin{array}{l}\text { The } 2017 \text { Ljubljana } \\
\text { Declaration }\end{array}$ & $\begin{array}{l}\text { Sendai Framework for Disaster Risk } \\
\text { Reduction 2015-2030 } \\
\text { The } 2030 \text { Agenda-Sustainable } \\
\text { Development Goals } \\
\text { The } 2015 \text { Paris Agreement on Climate } \\
\text { Change } \\
\text { ISDR-ICL Sendai Partnerships } \\
\text { 2015-2025 for disaster risk reduction }\end{array}$ \\
\hline
\end{tabular}

of root causes and risk drivers of landslides, particularly those related to land use, land development, and the consequent exposure of vulnerable communities to landslides as a result of population growth and lack of territorial management. To better understand and reduce landslide disaster risk, appropriate and periodic science-based risk assessments should be undertaken and better networking must be sought to enhance the interaction of all stakeholders. Cognizant of the fact that landslide disaster risk reduction is a cross-cutting concern, landscape mitigation has to be addressed by considering multiscale (with particular emphasis on local level), multihazard, transdisciplinary perspectives. Multiple speakers advocated an integrated approach on disaster risk research, a structure that is most likely to guarantee the codesign and coproduction of knowledge needed to strengthen decision making and practice for the benefit of society.

Because the purpose of the Sendai Framework is "the substantial reduction of disaster risk and losses in lives, livelihoods and health and in the economic, physical, 
social, cultural and environmental assets of persons, businesses, communities and countries" (UNISDR 2015, Paragraph 16), forum participants argued that the contributions of the ICL community should have an impact on changing behavior of governments, communities, and all people at risk with regards to landslides. This goal is best attained by providing a set of guidelines on policy making, educational tools, and risk awareness messages. Policy guidelines inform governments at all levels-local, national, regional - where investments have to be made to reduce vulnerabilities that are the real cause of disasters. Educational tools and key advocacy messages can be widely disseminated in different languages, in the schools, through the media, and through existing regional and thematic ICL networks.

During a round table discussion organized on 31 May 2017 as a follow-up to the high-level panel discussion, participants in WLF4 and five new signatory members of the ICL-Sendai Partnerships examined an action plan to support the implementation and further development of the Sendai Partnerships. This initiative would contribute in an effective way to the Sendai Framework. Moreover, a review was undertaken of the expected outcomes of WLF4, and the potential contributions of ICL to preparations for the 5th World Landslide Forum (WLF5), planned for Kyoto in November 2020. The 2017 Ljubljana Declaration on Landslide Risk Reduction also was adopted by 295 international organizations and the concept framework of the Kyoto 2020 Commitment was endorsed (Sassa 2017b).

A summary of the 2017 Ljubljana Declaration on Landslide Risk Reduction includes these major points enshrined the conference document. The participants:

- addressed the challenges of landslide disaster risk. They examined how landslide knowledge, technology, and investigation can be enhanced and applied to reduce vulnerability and exposure and to build the resilience of persons, communities, and countries to landslide disasters that, like other disasters triggered by natural hazards, undermine efforts to achieve the sustainable development goals of the 2030 Agenda for Sustainable Development; noted that landslides are a complex natural phenomenon of many types and varieties that can be triggered by earthquakes, volcanic eruptions, heavy and recurrent rainfall, typhoons, hurricanes, wildfires, snowmelt, sometimes exacerbated by anthropogenic activities and developments such as construction of roads and waterworks and mining. They recalled that submarine landslides are able to generate tsunamis and represent a major hazard to coastal areas;

- underlined that landslides, which occur on land and at sea, continue to pose considerable risks to humankind, to human settlements, and to livelihoods and economies in mountains, cities, coasts, and islands. They further emphasized that people most exposed to, and affected by, landslide disasters are disproportionately the poor, marginalized, and vulnerable, including women and children;

- cautioned that climate change and variability are expected to increasingly affect the frequency and extent of heavy rainfall and wildfires at local and regional levels with an enhanced potential for landslide occurrence. The combined effects of natural phenomena and human adverse activities, which are often associated with a rise in the vulnerability and exposure of urban and rural settlements and agglomerations, are increasing landslide risk throughout the world;

- reiterated that understanding landslides, their associated risks, and the vulnerability of societies requires an integrated and multidisciplinary approach that includes contributions from natural, social, and engineering sciences as well as local and traditional knowledge;

- recognized and welcomed the ISDR-ICL Sendai Partnerships 2015-2025 for Global Promotion of Understanding and Reducing Landslide Disaster Risk that was adopted as a voluntary commitment to the United Nations World Conference on Disaster Risk Reduction, held in Sendai, Japan, 14-18 March 2015. Forum attendees affirmed that this partnership is a supporting tool for the implementation of the Sendai Framework for Disaster Risk Reduction 2015-2030. They greet and commend the numerous partners who have adhered to these partnership relationships. They recognize, with great satisfaction, the progress made by the Partnerships during the first biennium of its life. Participants committed themselves to pursue and support further implementation of partnership interactions, including through building on the 2012 ICL Strategic Plan 2012-2021;

- recognized with deep appreciation the concrete actions and cooperative activities carried out by the ICL family, which include (but are not limited to) pathways created through ICL members, the IPL, and the IPL projects, the ICL supporting organizations, the ICL regional and thematic networks, the ICL World Centres of Excellence on Landslide Risk Reduction, the ICL University Twinning (UNITWIN) Cooperation Programme in the framework of the UNITWIN/UNESCO Chairs Programme, the Landslide School Network, ${ }^{3}$ and the Landslides journal and other ICL publications. Forum activists valued the most recent output, which is illustrated by the ISDR-ICL Landslide Interactive Teaching Tools;

\footnotetext{
${ }_{3}$ Further information can be found at: http://iplhq.org/category/iplhq/ ipl-ongoing-project/ and http://wlf5.iplhq.org/.
} 
- reiterated their call upon related governmental, nongovernmental, and international programs and initiatives from natural, engineering, human, social, and economical sciences, public and private, to continue promoting science and technology and their applications to landslide disaster risk mitigation by supporting and joining the ISDR-ICL Sendai Partnerships;

- looked forward to the initiation and furthering of the processes that lead to the organization of the 5th World Landslide Forum (WLF5) in 2020;

- believe that, in the perspective of, and during the preparations for WLF5, an opportunity must be found to mobilize (in the medium and long term) a global alliance that can accelerate and incentivize action for landslide risk reduction. They therefore urge putting in place a mechanism to that effect and call for a commitment, the Kyoto 2020 Commitment for Global Promotion of Understanding and Reducing Landslide Disaster Risk, to be finalized during the preparatory activities for WLF5 and adopted during WLF5 in order to serve this purpose;

- therefore, submitted the 2017 Ljubljana Declaration on Landslide Risk Reduction to UNISDR for endorsement as a further commitment on the part of the global landslide community to the Sendai Framework for Disaster Risk Reduction 2015-2030.

\section{Future Directions: The 5th World Landslide Forum, Kyoto 2020, and the Kyoto Commitment}

In seeking to further advance the contributions of the ISDRICL Sendai Partnerships to landslide disaster risk reduction and management, the ICL community wishes to forge an agreement, the Kyoto 2020 Commitment (K2020C), during the WLF5. The basic concept of K2020C is to create a longterm, wider, and stronger framework for the global landslide risk reduction network. It is named as the Kyoto 2020 commitment of the World Landslide Community to the ISDR-ICL Sendai Partnerships 2015-2025, the Sendai Framework for Disaster Risk Reduction 2015-2030, the 2030 Agenda-Sustainable Development Goals, and the 2015 Paris Agreement on Climate Change.

Initial fields of cooperation in research and capacity building, coupled with social and financial investment are identified as follows:

1. Development of people-centered early warning technology for landslides, especially within a changing climate context;

2. Development of hazard and vulnerability mapping and landslide risk assessment, as part of multihazard risk identification and management;
3. Development of improved technologies for monitoring, testing, analyzing, simulating, and producing effective early warning for landslides;

4. Development of international landslides teaching tools;

5. Open communication with society through integrated research, capacity building, knowledge transfer, awareness raising, training, and educational activities to enable societies to develop effective policies and strategies for reducing landslide disaster risk; and

6. Development of new initiatives to study research frontiers in understanding landslide disaster risk. These cutting edge explorations would examine the effect of climate change on large-scale landslides, the mechanisms and dynamics of earthquake-induced submarine landslides as tsunamigenic sources, catastrophic megaslides, and so forth.

Open Access This article is distributed under the terms of the Creative Commons Attribution 4.0 International License (http://crea tivecommons.org/licenses/by/4.0/), which permits unrestricted use, distribution, and reproduction in any medium, provided you give appropriate credit to the original author(s) and the source, provide a link to the Creative Commons license, and indicate if changes were made.

\section{References}

Sassa, K. 2004a. The International Consortium on Landslides. Landslides 1(1): 91-94.

Sassa, K. 2004b. The International Programme on Landslides. Landslides 1(2): 95-99.

Sassa, K. 2006. 2006 Tokyo action plan-Strengthening research and learning on landslides and related earth system disasters for global risk preparedness. Landslides 3(4): 361-369.

Sassa, K. 2009. Report of the 2008 First World Landslide Forum on 18-21 November 2008 at UNU, Tokyo. Landslides 6(3):167-179.

Sassa, K. 2012. ICL strategic plan 2012-2021-To create a safer geoenvironment. Landslides 9(2): 155-194.

Sassa, K. 2016. Implementation of the ISDR-ICL Sendai Partnerships 2015-2025 for global promotion of understanding and reducing landslide disaster risk. Landslides 13(2): 211-214.

Sassa, K. 2017a. The Fifth World Landslide Forum-Implementing and monitoring the ISDR-ICL Sendai Partnerships 2015-2025. Landslides 14(3): 1282-1288.

Sassa, K. 2017b. The 2017 Ljubljana declaration on landslide risk reduction and the Kyoto 2020 commitment for global promotion of understanding and reducing landslide disaster risk. Landslides 14(4). Preface.

Sassa, K., P. Canuti, C. Margottini, and Y. Yin. 2012. The Second World Landslide Forum, Rome, 2011, and the Third World Landslide Forum, Beijing, 2014. Landslides 9(2): 285-297.

Sassa, K., Y. Yin, and P. Canuti. 2015. The Third World Landslide Forum, Beijing, 2014. Landslides 12(1): 177-192.

UNISDR (United Nations International Strategy for Disaster Reduction). 2015. Sendai framework for disaster risk reduction 2015 2030. Geneva: UNISDR. 